\title{
Recruitment of Homalaspis plana in intertidal habitats of central Chile and implications for the current use of Management and Marine Protected Areas
}

\author{
Miriam Fernández*, Juan Carlos Castilla \\ Estación Costera de Investigaciones Marinas, Departamento de Ecología, Facultad de Ciencias Biológicas, \\ Pontificia Universidad Católica de Chile, Casilla 114-D, Santiago, Chile
}

\begin{abstract}
Information about the life history of the stone crab Homalaspis plana was necessary to investigate the possible reasons for the failure of Marine Protected Area (MPA) and Management and Exploitation Area (MEA) in increasing stone crab abundance, in contrast with other exploited benthic species. In this study, we analyzed some aspects of the early life history of the stone crab, focusing especially on (1) recruitment patterns among habitats and between years in intertidal zones, (2) habitat preferences, including some intra- and interspecific interactions that may affect habitat use, and (3) intraspecific interactions that may affect survival. We also evaluated the percent cover of suitable habitats for juvenile stone crabs in a MPA and a MEA. Sheltered habitats showed higher densities of juvenile $H$. plana than exposed areas, and sand with boulders showed the highest crab densities, followed by shell hash with boulders. Differences in mean densities were detected for all benthic stages among sheltered substrates, except for megalopae. Bare substrates (without boulders) showed the lowest density. Throughout the settlement period, abundance of smaller instars $(<\mathrm{J} 2)$ was 3 times higher in 1995 than in 1996, while densities of >J4 were twice as high in 1996 than in 1995. Neither intra- nor interspecific space competition seems to explain the distribution of juvenile stone crabs in the field. However, cannibalism among juveniles may have an important effect on survival. Cannibalism among juveniles is density-dependent, and may have greater effects as the abundance of larger conspecifics increases since mutual interference does not affect proportional prey mortality per predator. We suggest that losses are high in low quality habitats (probably through emigration, predation or habitat disturbance due to wave impact), and cannibalism is an important source of mortality in high quality habitats (where crab density is high). Although substrate type and post-settlement processes can help explain the distribution of juvenile stone crabs, wave action seems to be the major determinant of juvenile distribution. Neither sheltered habitats nor the most suitable substrate are common in the MPA and MEA studied. These factors are not currently being considered in the assignation of MEAs or planning of MPAs, although they could explain the lack of effect of both protection strategies in increasing the abundance of the stone crabs in Chile in comparison to other exploited benthic species.
\end{abstract}

KEY WORDS: Habitat quality · Stone crab · Life history · Recruitment · Marine Protected Areas · Management Areas · Chile

Resale or republication not permitted without written consent of the publisher

\section{INTRODUCTION}

The stone crab Homalaspis plana is found all along the coast of Chile, where this species supports an im-

*E-mail: mfernand@genes.bio.puc.cl portant artisanal fishery. A decline in catch per unit of effort of the stone crab has been observed in some fishing grounds of central Chile since 1992 (Fernández \& Castilla 1997), but to date no serious efforts have been made to regulate the fishery or avoid overexploitation except for the implementation of Management and Ex- 
ploitation Areas for Benthic Resources. Current management plans for benthic resources in Chile have 2 schemes: one involves the traditional, open-access fishing grounds, and the second the novel Management and Exploitation Areas (MEAs; Castilla 1994). MEAs are exclusive-use-right fishing grounds assigned to the Fishermen's Unions (Castilla 1994, Payne \& Castilla 1994). In the last few years the number of MEAs has increased, and there are currently more than 150 MEAs along the coast of Chile. Marine reserves are still rare, but there is a plan to design a network of Marine Protected Areas (MPAs) in Chile (MPA, Castilla 1996, González et al. 1997).

In the MEAs and marine reserves, abundance of parental stocks of most exploited species is higher because of low removal rates (Castilla \& Durán 1985, Moreno et al. 1986, Durán \& Castilla 1989, Godoy \& Moreno 1989, Castilla et al. 1998a, Castilla 1999). The underlying assumptions of exclusive-use-right fishing grounds and the MPAs are that they contain enough adults to assure larval production, and therefore have the potential for exporting larvae or juveniles to surrounding exploited zones. Furthermore, it is also assumed that marine reserves and MEAs include a variety of habitats that are capable of maintaining juvenile and adult production of most exploited benthic species. However, recent studies have shown no effect of closed areas (a marine reserve and a MEA) on the abundance of adult Homalaspis plana (Fernández \& Castilla 1997). It has been hypothesized that the current size of the closed areas studied may not be appropriate to have an effect on mobile species (Fernández \& Castilla 1997), although there is no information on movement rates for $H$. plana. An alternative hypothesis is that the sites selected for MPAs and MEAs may not offer suitable habitats for settlement and recruitment of the stone crab, or for the adults, since the sites were initially selected for locos Concholepas concholepas (Castilla et al. 1998a and references therein). Larval supply may affect the spatial distribution of crab recruits (Eggleston \& Armstrong 1995), and habitat quality is known to affect preferences for substrates (especially among strong-swimming larvae such as crabs; Castro 1978, Botero \& Atema 1982, Bell \& Westoby 1986, Herrnkind \& Butler 1986, Hedvall et al. 1998) and also post-settlement survival of juvenile crabs (Keough \& Downes 1982, Luckenbach 1984, Eggleston et al. 1990, Fernández et al. 1993a, Eggleston \& Armstrong 1995, Moksnes et al. 1997, 1998). Inter- and intraspecific interactions after settlement also play a critical role in determining abundance of juvenile crabs (interspecific predation, and emigration in response to inter- and intraspecific aggressive interactions; Iribarne et al. 1994, Visser 1997). Finally, intraspecific predation (cannibalism) is an important source of mortality in refuge habitats (Fernández et al. 1993a,b, Moksnes et al. 1997, 1998, Fernández 1999, Moksnes 1999). Thus, habitat quality may play an important role in the recruitment and population dynamics of many marine species through different processes, provided that larvae are available. Any attempt to protect species affected by human impact needs to take into account the life history of the assemblage that is to be protected (Allison et al. 1998), and the availability of suitable habitats.

Little is known about the life history of the stone crab Homalaspis plana (but see Fagetti 1960, Antezana et al. 1965, Morales \& Antezana 1983, Carvacho et al. 1995), and particularly about its recruitment dynamics and habitat requirements. In this study, we analyzed some aspects of the early life history of the stone crab, focusing especially on (1) recruitment patterns among habitats and between years in intertidal zones of central Chile, (2) habitat preferences, including some intra- and interspecific interactions that may affect habitat use, and (3) intraspecific interactions that may affect survival. We also evaluated the percent cover of suitable habitats in a MPA and a MEA, in order to assess if an increase in production of juveniles of $H$. plana can be expected as a result of the current protection of habitats and adults from human use and exploitation. The results of this work will contribute not only to the understanding of the early life history and ecology of this exploited species, but also to management and conservation plans at the multispecies level in general.

\section{MATERIAL AND METHODS}

Field studies. Field studies were conducted in central Chile to investigate (1) whether patterns of stone crab recruitment differed among habitats in the intertidal zone, and (2) the availability of suitable habitats in closed areas (MPA and MEA). Size at instar (and growth rate) was also estimated from these samples since there was no previous information for this species. This study was conducted in the mid-low intertidal zone, within a $9 \mathrm{~km}$ area of coastline around Las Cruces (central Chile, 33 $30^{\prime} \mathrm{S}$; Fig. 1).

Crab density: Field studies were conducted to investigate whether crab recruitment differed among habitats in the intertidal zone. One sheltered site in the Las Cruces area (containing sand and boulders as substrate in the intertidal zone, Antezana et al. 1965; Fig. 1) was chosen, and settlement and crab density were regularly monitored throughout 2 settlement seasons. The rationale of covering 2 settlement seasons was to assess interannual variability in crab recruitment due to variations in larval supply. Samples were taken from 


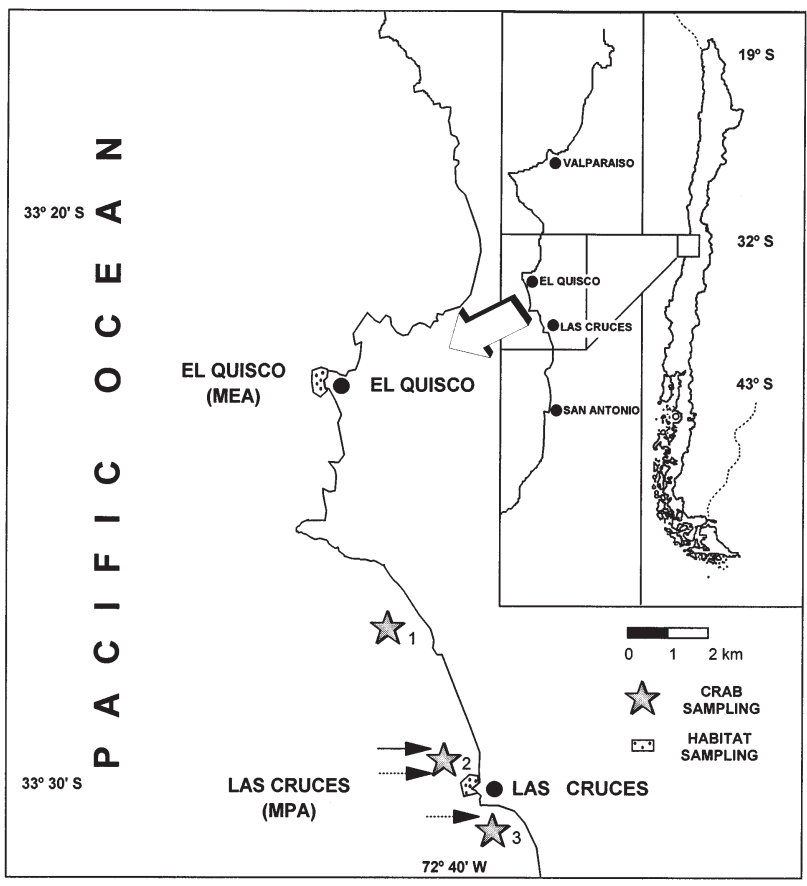

Fig. 1. Map of study area. Closed areas of El Quisco (Management and Exploitation Area [MEA]) and Las Cruces (Marine Protected Area [MPA]) are marked (not to scale). Sampling sites for monitoring crab density, or assessing habitat availability are indicated. Crab samples were taken from around Las Cruces (within $9 \mathrm{~km}$ ), and none of them were inside the MPA. Inside both closed areas we quantified the percent cover of the different habitat types. North and south of Las Cruces we sampled different open access areas, each containing different habitat types. In Area 1, we sampled only 1 site (S-E). In Area 2, we sampled 3 sites (SH/B-E, S-T, and S/B-T). In Area 3, we sampled 6 sites (SH-E, R-E, R-T, R/B-E, R/B-T, SH/B-T). E = exposed; $\mathrm{T}=$ sheltered; $\mathrm{S}=$ sand; $\mathrm{S} / \mathrm{B}=$ sand with boulders; $\mathrm{SH}=$ shell hash $; \mathrm{SH} / \mathrm{B}=$ shell hash with boulders; $\mathrm{R}=$ rock platforms; $\mathrm{R} / \mathrm{B}=$ rock platforms with boulders. We measured wave impact at 2 sites, 1 located in Area 2, the other in Area 3. ( $\longrightarrow$ ): location of the permanent (2 yr) monitoring site; $(\cdots \cdots)$ ): 2 sites where monthly samples were conducted between 1994 and 1995

November 1994 to March 1995, and from November 1995 to March 1996 to determine patterns of settlement and post-settlement survival over a period of time (see sampling method below). As we started sampling in November 1994, exposed (E) and sheltered (T) intertidal sites containing different substrates were identified and selected as sampling sites. The substrate types identified were: sand (S), sand with boulders (S/B), shell hash (SH), shell hash with boulders (SH/B), rock platforms (R), and rock platforms with boulders (R/B). Boulders ranged from $15 \mathrm{~cm}$ to $1 \mathrm{~m}$ in diameter. Site and habitat will be used in the manuscript interchangeably. Each site (or habitat) identified resulted from different combinations of substrate types and wave exposure, and represented independent, discrete portions of the intertidal zone within the 5 mile study area. Each habitat covered $>100 \mathrm{~m}$ of coastline, and although crab migration among habitats may take place, it may be an important process only in the limit between habitats. Not all substrates and exposure combinations were found. Thus, the sites sampled were: S-E, S-T, S/B-T, SH-E, SH/B-E, SH/B-T, R-E, R-T, R/B-E, R/B-T. The MPA is also located in Las Cruces, but crab samples were always taken outside the MPA, and outside the MEA of El Quisco, located approximately $18 \mathrm{~km}$ north of Las Cruces (Fig. 1). Samples were not taken in the MPA and MEA because of limited availability of habitat types (especially sheltered sites) and because removal of animals is not allowed. Thus, the MPA and MEA were only surveyed to assess the proportion of different substrate types available, and habitat types suitable for recruitment of the stone crab.

These habitats were first sampled in January 1995, when newly settled crabs became evident, and were then monitored monthly afterward. Although crabs were found in subsequent samplings at only 3 sites (including the 2 yr monitoring site) sampling continued throughout the 1994-95 settlement season (Fig. 1). Boulders alone (multi-layers of boulders) were found in only 1 small portion of the coast (approximately $10 \mathrm{~m}$ ) in 1 exposed site, and were not sampled because of the difference in the spatial scale with the other habitats (but crabs were not present when we made the first assessment). In order to quantify crab density, random samples were taken in the intertidal zone during low tide, using a $0.3 \times 0.3 \mathrm{~m}$ quadrat (at least 5 replicates per habitat each time). When the habitats contained boulders, only areas with $100 \%$ boulder cover (a layer of boulders) were sampled to reduce variability due to habitat quality. A frame was placed in the sampling area after the boulders were removed (boulders $<50 \mathrm{~cm}$ diameter) and then the sediment (sand, shell hash) was collected. Using this method we expect that none of the stone crabs escaped since they move very slowly. In the laboratory, crabs were sorted, counted, and measured (carapace width [CW]). We sorted the megalopae and crabs in the laboratory to better detect small individuals, especially in shell hash. On bare platforms, crabs were collected in the field, and were easily detectable on hard substrates. Carapace color was also recorded.

The size at instar was obtained using size frequency distributions from Site S/B-T between January and March 1995. We conducted a visual analysis, with the goal of determining approximate size at instar for the first 3 benthic stages, as well as growth patterns during the first summer of benthic life. This information was necessary not only because there was no previous information about early life history for Homalaspis plana, but also for the analysis of crab density and intraspecific interaction experiments shown below. 
All substrate types were not found for each exposure type, resulting in 2 different ANOVA models. We used a 2-way ANOVA to test for the effect of substrate type and exposure on total crab density. The most suitable habitat (S/B, see 'Results') was found only in sheltered areas, and bare shell hash only in exposed habitats, thus they could not be included in the 2-way ANOVA. Since our goal was to determine the most suitable habitats, sand with boulders needed to also be included in the comparison. We conducted a 1-way ANOVA to compare the effect of substrate type on total crab density, and also on megalopae, and juvenile density in sheltered areas. Two-way ANOVAs were also used to compare crab density (total, megalopae, and juvenile stages) among sites throughout the post-settlement period (independent variable post-settlement time, which considered the time elapsed since settlement peaked, in January). This analysis was done using samples taken between January and March 1995, and allowed the assessment of habitats with higher rates of survival after settlement. Finally, 2-way ANOVAs were also used to test for differences in mean crab density (megalopae, J1 and larger benthic stages) between November and March among habitats, and between 2 consecutive years in the same habitat (S/B-T). The latter analysis was conducted to determine interannual variability in juvenile stone crab abundance. In all cases, the factors of the ANOVAs were considered random, and Student-Newman-Keuls tests were used for a posteriori comparisons (Zar 1996).

The rocky shore of central Chile is very exposed to wave action (Castilla et al. 1998b). In order to characterize the sampling sites, wave impact was quantified using water velocity recorders (dynamometers; see Castilla et al. 1998b for descriptions of the device). This device allowed us to obtain instantaneous estimates of wave impact. Measurements were conducted at 2 sites in the Las Cruces area (1 exposed and 1 sheltered); those locations were regular monitoring sites for crab density during the first summer (Fig. 1). The characterization of the actual sampling sites was broad since no actual measurements of them were conducted. Although small variations in wave exposure may occur within 1 site, we always sampled exposed areas within the exposed sites, and vice versa. The devices (3 per location) were attached to rocky platforms or large boulders during low tide, and covered by water only during high tide. Wave impact was measured during the next low tide. Measurements were conducted during 1 calm, 1 moderately windy and 1 windy day (qualitative assessment). We always conducted the measurements with northern winds. One device was lost at the exposed site during the second trial, and another at the sheltered site during the last day of the experiment. We conducted a 2-way ANOVA to assess whether wave impact differed depending on wind strength and between exposed and sheltered sites. The exposed and sheltered sites were randomly selected among the many available (2 levels for the wave exposure factor), and also the days on which each measurement was going to be conducted (3 levels for wind factor: calm, intermediate, and windy). Thus, we treated both factors as random.

Spatial micro-scale distribution of juvenile crabs: In order to assess whether the presence and abundance of other species might be correlated to the spatial distribution of juvenile stone crabs, $0.1 \times 0.1 \mathrm{~m}$ quadrats were sampled as described above. Samples were conducted at Site S/B-T. The small quadrat size was chosen, first, because density of coexisting species in some cases was high, second, because some species were patchily distributed at small spatial scales (relative to boulder sizes), and finally because larger quadrats would have been hard to sample due to the high mobility of some species. We are not aware of migration between the intertidal and subtidal zone of the species included in this analysis. Sampling was conducted in mid-January, when newly recruited crabs as well as larger stone crab juveniles were found. Boulders were removed, the sediment collected, and in the laboratory juvenile stone crabs were sorted and counted. Abundance of coexisting species in each quadrat $(n=36)$ was qualitatively assessed (categories: abundant, intermediate, low, and absent) in the field. We selected the 3 most conspicuous species: Tegula atra, Petrolisthes spp., and amphipods (several species), and their abundance was qualitatively assessed. The density of these species was in some cases so high that even sampling quantitatively small quadrats was difficult (high mobility of some of the species, such as Petrolisthes spp. crabs and amphipods). Thus, abundance categories were assigned numbers from 1 (absent) to 4 (abundant) and a 1-way ANOVA was used to test for the effect of relative abundance of co-existing species on abundance of juvenile crabs. Two tests were conducted, 1 for each dependent variable: density of juvenile crabs $<\mathrm{J} 2$ and density of juveniles $>\mathrm{J} 4$.

Estimates of habitat types available in closed areas (MPA and MEA): Percent cover of different habitat types were estimated in the El Quisco MEA and Las Cruces MPA, with the goal of determining if protected areas contain suitable habitats for stone crab recruitment. These 2 sites were selected because they are exemplary cases in Chile for MPAs (>15 yr of actual human exclusion, Castilla 1999) and MEAs (exploitation rate has been low for $>5$ yr, Castilla et al. 1998a). Four observers carried out independent estimates of percent cover of the different habitat types found in the protected areas, and from those estimates mean percent cover of each habitat was estimated. 
Laboratory experiments. Laboratory experiments were conducted to assess substrate preference and the effects of inter- and intraspecific interactions on substrate choice and on juvenile Homalaspis plana survival.

Substrate preference: Laboratory experiments were conducted under still water conditions to assess preference of megalopae and juvenile crabs for the natural substrate types available in the intertidal zone. Substrates used in the experiments were: (1) sand, (2) shell hash, and (3) cobbles. Due to experimental constraints, cobbles were used to replace boulders. Crabs used in the experiment were megalopae to $20 \mathrm{~mm} \mathrm{CW}$ juveniles. For each habitat combination (2 choices), half of the tank was covered with each substrate type. A single crab was placed in the center (between the 2 habitats) at the beginning of the experiment. The tank size varied depending on crab instar stage $(15 \times 20 \times 30 \mathrm{~cm}$ for megalopae, first and second instar crabs; $20 \times 30 \times$ $30 \mathrm{~cm}$ for crabs 8 to $10 \mathrm{~mm} \mathrm{CW}$; and $30 \times 30 \times 30 \mathrm{~cm}$ for crabs 16 to $19 \mathrm{~mm} \mathrm{CW}$ ), and tanks were filled with seawater. Crab size used in each particular habitat combination and number of replicates are listed in Table 1. Trials were run for $24 \mathrm{~h}$, and at the end of the experimental period the habitat occupied by each stone crab was recorded. Contingency tables were used to test if habitat selection was independent of instar stage (the number of crabs that selected each substratum is also reported).

Interspecific competition: We conducted laboratory experiments in order to assess whether Petrolisthes spp., the other most common and abundant crab species in the intertidal zone, affected the distribution of juvenile Homalaspis plana. We hypothesized that at high crab density, space is a limiting resource and the distribution of both species may be affected by space competition. Tanks $(30 \times 30 \times 30 \mathrm{~cm})$ were filled with shell hash (the preferred substrate, see 'Results'). Two cobbles were placed on each side of the tank, and then 3 Petrolisthes spp. and 2 juveniles of $H$. plana were

Table 1. Homalaspis plana. Number of replicates used for habitat selection experiments conducted under laboratory conditions for megalopae and benthic stages of the stone crab and for each habitat combination. J1: first instar crabs; J2: second instar; J4: fourth instar. Size range $(\mathrm{mm})$ for each benthic stage is indicated within parentheses. Abbreviations as in Fig. 1

\begin{tabular}{|lrcr|}
\hline Crab stage & \multicolumn{3}{c|}{ No. of replicates } \\
& S/SH & S/B & B/SH \\
\hline Megalopae & 5 & 10 & 7 \\
J1 (3.2-3.8) & 10 & 10 & 10 \\
J2 (4.4-5.4) & 10 & 10 & 15 \\
J4 (8-10.1) & 10 & 10 & 10 \\
>J4 (16-19) & 10 & 10 & 6 \\
\hline
\end{tabular}

added (1 second instar [J2] and 1 third instar [J3], see 'Results' for definition of each instar stage). In order to detect competition for space, we used the highest densities found in the field for both species. The size gap between both species also reflected the field conditions. These 2 instars were the most abundant at the time the experiment was conducted, and small with respect to Petrolisthes spp. Mean size of the Petrolisthes spp. used in the experiment was $12.2 \mathrm{~mm}$ $(\mathrm{SD}=2.49)$. Eight replicates were run, and after $24 \mathrm{~h}$ the habitat selected by each crab was recorded.

Intraspecific interaction: Laboratory experiments were also conducted to assess whether intraspecific interaction affects substrate preference and survival of juvenile Homalaspis plana. Two types of experiments were conducted: the first, to evaluate if interaction among conspecifics may affect habitat choice, especially of the smaller, more vulnerable individuals, and the second, to assess the potential for cannibalism as a result of intraspecific interactions.

Effect on habitat choice: The experimental setup was the same as the one described above for interspecific interactions, except for the combination of crab stages. We conducted this experiment because in other crab species (e.g. Dungeness crab, Iribarne et al. 1994) density-dependent emigration affects abundance of juvenile crabs in the intertidal zone. Two types of instar combinations were used, based on the relative abundance of the 3 instars when they co-occur: (1) $2 \mathrm{~J} 1$ and 1 J2 (10 replicates), and (2) 2 J1, 1 J2 and 1 J3 (11 replicates). After $24 \mathrm{~h}$ the habitat selected by each crab was recorded.

Cannibalism: Laboratory experiments were conducted to assess whether cannibalism among juveniles in the first year of benthic existence may occur in $\mathrm{Ho}$ malaspis plana, and whether this process can explain patterns of recruitment observed in the field (see 'Results'). The rationale for considering only cannibalism among juveniles was 2 -fold. On the one hand, only juveniles are found in the intertidal zone so cannibalism between year classes is less likely. On the other hand, cannibalism among juveniles is an important cause of mortality in other crab species (e.g. Fernández et al. 1993a,b, Moksnes et al. 1997, Fernández 1999), and may also be in $H$. plana. The experiments were conducted using small tanks $(30 \times 30 \times 30 \mathrm{~cm})$. The bottom of the tank was covered with a layer of shell hash (preferred substrate, see 'Results'), and J1 or J2 crabs were used as potential prey. In order to assess whether prey density can affect cannibalism rate, prey densities were $1,2,3,4,6$, and 8 per tank for each instar stage. Predators were larger conspecifics (for J1 prey: $\bar{x}=$ $11.91 \mathrm{~mm} \mathrm{CW}, \mathrm{SE}=0.17$; for J2 prey: $\bar{x}=18.14 \mathrm{~mm} \mathrm{CW}$, $\mathrm{SE}=0.21$ ), and a single predator per tank was used. Trials were run for $24 \mathrm{~h}$, after which surviving prey 
were recorded. This experiment was controlled by placing the same number of prey in tanks without predators, to control for cannibalism among the prey. Predators were starved for $48 \mathrm{~h}$ before the experiment. At least 5 replicates were done for each combination of prey instar and density. We used a 2-way ANOVA (Model I) to test for the effect of prey size and prey density on the 2 response variables: number of prey eaten and proportional mortality. Square root and arcsine transformations were utilized only when necessary to meet the assumptions of ANOVA.

Another experiment was conducted in order to assess if the interactions among predators could affect cannibalism rate. Field observations showed that when J2 was the most abundant instar stage, densities of larger conspecifics were also high. Interference among predators affects predation (Mansour \& Lipcius 1991, Iribarne et al. 1995) and cannibalism rate (Moksnes et al. 1997, Fernández 1999). Tank size, setup and experimental time followed the same protocol as in the previous experiment. J1 crabs were not used because they were not abundant when the experiment was done. Predators were larger conspecifics $(\bar{x}=17.9, \mathrm{SD}=$ 1.73). Treatments were 1 or 3 predators per tank. Eight prey were used in each tank. A 1-way ANOVA was used to test for differences among treatments. Proportional mortality data were square-root transformed to meet the assumptions of the ANOVA model.

\section{RESULTS}

\section{Field studies}

Crab density and size

Growth rate and size at instar. The first peak of settlement occurred between December 1994 and January 1995 . The modal size interval was $3-5 \mathrm{~mm}$ between early and mid-January, remained at $4-5 \mathrm{~mm}$ in early February (with other modes at $7-8$ and $12-13 \mathrm{~mm}$ ), and increased to $5-7 \mathrm{~mm}$ in mid-February and mid-March (with a second mode at $8-10 \mathrm{~mm}$; Fig. 2). In January, samples were composed mostly of crabs ranging between 3 and $6 \mathrm{~mm} \mathrm{CW}$ (Fig. 2); within this size range there were 2 modes. The first modal class interval was $3.4 \mathrm{~mm}$ (range between 3 and $3.8 \mathrm{~mm}$ ) and the second between 4.6 and $4.8 \mathrm{~mm}$ (Fig. 2, smaller scale). These 2 modes were also present in February, and we suggest that they correspond to first (J1) and second (J2) instar crabs, respectively. We also suggest that the mode interval $6.4 \mathrm{~mm}$ (5.8 and $7.2 \mathrm{~mm}$ ) observed in February (Fig. 2) corresponds to third (J3) instar crabs. Finally, we were able to identify 2 other modes in mid-February that may represent

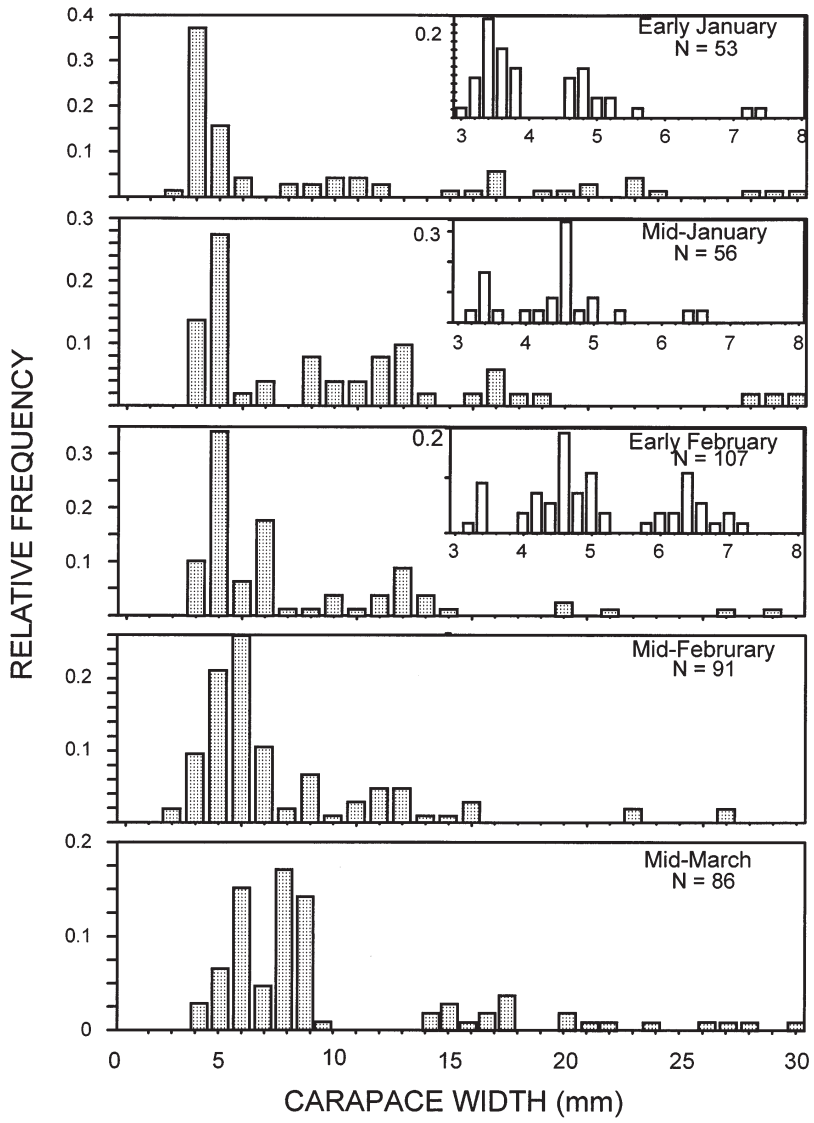

Fig. 2. Homalaspis plana. Size frequency distribution throughout the summer 1995. The smaller graphs in the top 3 panels show the modes for the smaller instar stages

fourth (J4, 8 to $9 \mathrm{~mm}$ ) and fifth instars (J5, 12 to $13 \mathrm{~mm}$; Fig. 2). In the laboratory, crabs that fell within the size interval of $\mathrm{J} 3(\bar{x}=7.1 \mathrm{~mm})$ showed a mean size of $8.8 \mathrm{~mm}$ when molted $(\mathrm{n}=6)$, and crabs identified as $\mathrm{J} 4$ $(\bar{x}=9.2 \mathrm{~mm})$ showed a $2 \mathrm{~mm}$ increase in size after molting $(\mathrm{n}=9)$, supporting our suggestion of size at instar for J4 and J5 based on size frequency distributions. However, for all the analyses we pooled all the instars $>\mathrm{J} 4$ because our size frequency distribution data did not allow a clear discrimination between larger instars. These results suggest that it may take between 60 and $70 \mathrm{~d}$ to grow from megalopae to the fifth instar stage (12 to $13 \mathrm{~mm} \mathrm{CW} 5$ molts).

Crab density. Crab density was monitored (1) shortly after settlement in different intertidal habitat types, (2) during the post-settlement period (1995) at 3 locations, and (3) between years for the most suitable habitat (1994-95 and 1995-96 post-settlement seasons).

Mean crab density was compared among sites with different types of substrate in sheltered and exposed areas. A significant interaction between exposure and substrate on total crab density was found (ANOVA, $F=5.5, \mathrm{df}=3,33, \mathrm{p}=0.0035)$. The interaction was 
significant due to differences in crab density among substrates with different degrees of exposure on the shore. Rock platforms are colonized by crabs only if they are sheltered. Crabs were found in shell hash with boulders in exposed and sheltered areas, although crab density was lower in the exposed site (Fig. 3). Wave impact was measured as an indicator of exposure in the 2 sampling sites (habitats: [1] sheltered [S/B-T] and [2] exposed [SH/B-E]). Wind strength did not have any effect on the measurements (ANOVA: $F=0.55$, $\mathrm{df}=2,10, \mathrm{p}=0.55$ ), but water velocity was 3 times stronger at the site we characterized as exposed (ANOVA: $F=24, \mathrm{df}=1,10, \mathrm{p}=0.039$ ). The interaction term was not significant $(F=1.55, \mathrm{df}=2,10, \mathrm{p}=0.26$ ).

At sheltered sites, differences in mean densities among substrates were detected for all benthic stages but megalopae (Fig. 3, Table 2). For J1 crabs, rock platforms showed the lowest density, followed by sand with boulders $(p<0.05)$. It is noteworthy that rock platforms with boulders showed the highest density of $\mathrm{J} 1$ and a relatively high density of megalopae, but no other instars were found there. It is also interesting to point out that although sand with boulders showed the highest total crab density, J1 density was not higher. The highest densities of $\mathrm{J} 2$ and larger instars were detected in sand with boulders $(\mathrm{p}<0.05)$.

Comparisons over the post-settlement period among 3 locations showed no differences in megalopae density among habitats, but differences across months were found; the interaction term was not significant

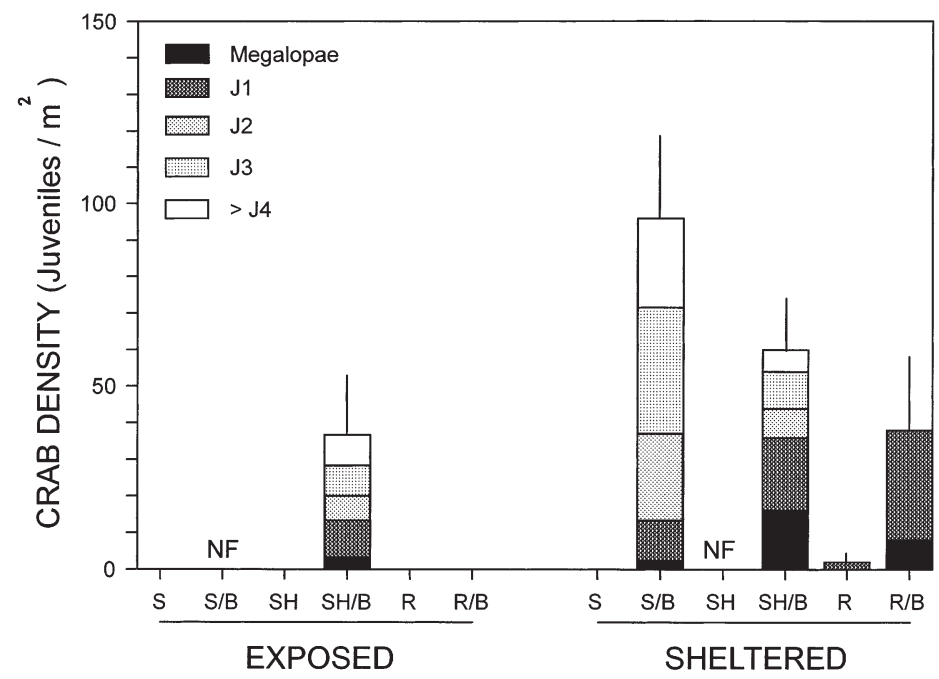

Fig. 3. Homalaspis plana. Density of megalopae and juvenile stone crabs by instar stage for the different substrate types detected at exposed and sheltered areas shortly after settlement peaked in mid-January 1995. For the first 3 types of substrate there were locations with bare substrate or with boulders on the main substrate (S/B, R/B, SH/B). NF: not found. Vertical lines: $1 \mathrm{SE}$ (for all groups together). Abbreviations as in Fig. 1
Table 2. Homalaspis plana. Results of 1-way ANOVAs conducted to test for the effect of substrate type (S, S/B, SH/B, R, $\mathrm{R} / \mathrm{B}$ ) on densities of megalopae and juveniles (different instar stages) in sheltered intertidal areas of central Chile. We included all the sheltered sustrates sampled in the analysis. All data were square-root transformed. Abbreviations as in Fig. 1

\begin{tabular}{|lccl|}
\hline Density by instar stage & $F$ & $\mathrm{df}$ & \multicolumn{1}{c|}{$\mathrm{p}$} \\
\hline Megalopae & 2.14 & 4,28 & 0.10 \\
$\mathrm{~J} 1$ & 4.05 & 4,28 & 0.010 \\
$\mathrm{~J} 2$ & 8.45 & 4,28 & 0.0001 \\
$>\mathrm{J} 4$ & 8.67 & 4,28 & 0.0001 \\
\hline
\end{tabular}

(Table 3, Fig. 4). Megalopae density was higher in January than in February and March. J1 and J2 crab densities decreased dramatically between January and February in exposed substrates, while the decrease for the sheltered substrates occurred in March, resulting in a significant interaction between habitat and postsettlement time (Table 3). In the case of J4, no differences across months were detected, but habitat did have an effect. Density of crabs $>\mathrm{J} 4$ was twice as high at Site S/B-T than at the other 2 sites.

Interannual variation in recruitment of the stone crab was monitored in the most suitable intertidal habitat (S/B). Megalopae were found earlier in 1995 than in 1996, resulting in a significant interaction between

Table 3. Homalaspis plana. Results of 2-way ANOVAs conducted to test for the effect of habitat and time elapsed from settlement (independent variable: post-settlement time) on densities of megalopae and juveniles (different instar stages) in the intertidal zone of central Chile. Habitats sampled: S/B-T; SH/B-E,T. Density of juvenile crabs was followed for 3 mo after settlement. All data were square-root transformed. Abbreviations as in Fig. 1

\begin{tabular}{|llccc}
\hline $\begin{array}{l}\text { Density by } \\
\text { instar stage }\end{array}$ & Factor & $F$ & $\mathrm{df}$ & $\mathrm{p}$ \\
\hline Total & & & & \\
& Post-settlement time & 4.61 & 2,44 & 0.015 \\
& Habitat & 19.4 & 2,44 & $<0.00001$ \\
& Interaction & 3.18 & 4,44 & 0.0223 \\
Megalopae & Post-settlement time & 9.6 & 2,44 & 0.0003 \\
& Habitat & 2.0 & 2,44 & 0.15 \\
& Interaction & 1.28 & 4,44 & 0.29 \\
J1 & Post-settlement time & 6.8 & 2,44 & 0.026 \\
& Habitat & 3.6 & 2,44 & 0.036 \\
& Interaction & 2.7 & 4,44 & 0.044 \\
J2 & Post-settlement time & 9.6 & 2,44 & 0.0004 \\
& Habitat & 19.97 & 2,44 & $<0.00001$ \\
& Interaction & 3.84 & 4,44 & 0.0092 \\
J4 & Post-settlement time & 1.74 & 2,44 & 0.186 \\
& Habitat & 7.48 & 2,44 & 0.002 \\
& Interaction & 0.58 & 4,44 & 0.676 \\
& & & & \\
\hline
\end{tabular}




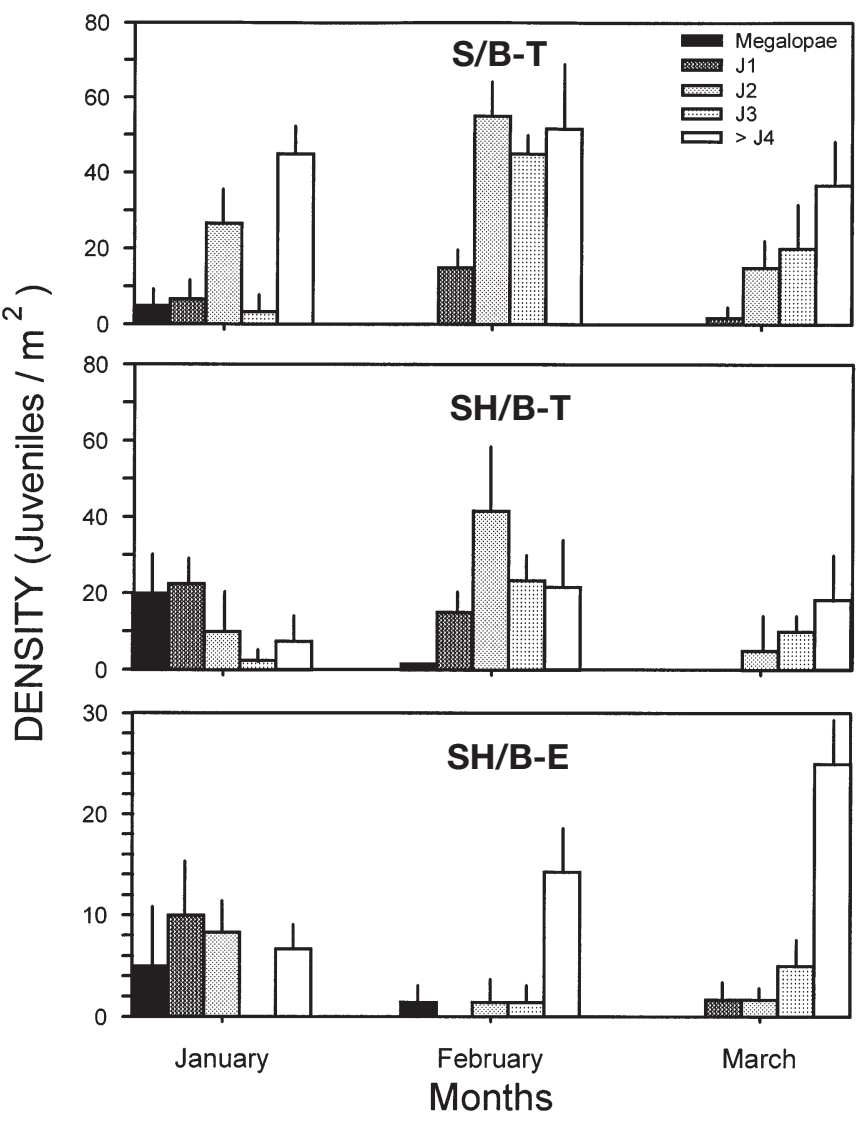

Fig. 4. Homalaspis plana. Density of megalopae and juvenile stone crabs by instar stage throughout 1 post-settlement season (January to March). Sites were selected because they contained distinctive habitats: S/B-T, SH/B-T, and SH/B-E. In all cases $100 \%$ boulder cover (over the different substrate types) was sampled. Vertical lines: 1 SE (for all groups together). Abbreviations as in Fig. 1

years and months (Table 4, Fig. 5). However, J1 were present since November in the 1995-96 season. Density of J1 crabs was not significantly different between years, but there were differences in density throughout the post-settlement period (Table 4, Fig. 5). Although there were evident settlement peaks (January), J1 crabs were observed between November and March, indicating a continuous but low recruitment. Pooling the months in which recruitment occurred (November to March) showed that mean density of recruits (megalopae and J1) throughout the settlement period was 3 times higher in 1995 than in 1996 (ANOVA: $F=5.6, \mathrm{df}=1,32, \mathrm{p}=0.024$ ). If J2 were also pooled with megalopae and J1, the 3-fold difference between 1995 and 1996 recruitment could still be observed (ANOVA: $F=9.5, \mathrm{df}=1,32, \mathrm{p}=0.004$ ). $\mathrm{J} 4$ were equally abundant during the post-settlement period, although differences between years were observed, with densities of $>$ J4 twice as high in 1996 than in 1995 (Table $4 ; \mathrm{p}=0.013$ ).
Table 4. Homalaspis plana. Results of 2-way ANOVAs conducted to test for the effect of post-settlement time and settlement year (1994-95 vs 1995-96) on density of juveniles (different instar stages) in 1 intertidal habitat of central Chile. The substratum was $\mathrm{S} / \mathrm{B}$ at 1 sheltered site, and density of juvenile crabs was followed for 5 mo (November to March). Data were log transformed

\begin{tabular}{|llrcc|}
\hline $\begin{array}{l}\text { Density by } \\
\text { instar stage }\end{array}$ & Factor & $F$ & df & $\mathrm{p}$ \\
\hline Megalopae & Year & 7.2 & 1,50 & 0.009 \\
& Month & 11.9 & 4,50 & $<0.0001$ \\
& Interaction & 9.9 & 4,50 & $<0.0001$ \\
J1 & Year & 2.3 & 1,50 & 0.13 \\
& Month & 3.2 & 4,50 & 0.02 \\
& Interaction & 1.9 & 4,50 & 0.113 \\
J4 & Year & 6.6 & 1,50 & 0.013 \\
& Month & 1.77 & 4,50 & 0.149 \\
& Interaction & 2.0 & 4,50 & 0.107 \\
\hline
\end{tabular}

Juvenile Homalaspis plana showed a variety of carapace colors. Although we were not aware of variations in the patterns of coloration for this species when the study began, we recorded crab colors from all the samples. Colors were classified as 'adult-like' and 'others'; 'others' included a variety of colors observed in juvenile stone crabs (white, brown, grey, and a combination of these colors in various patterns). Legs and chelae also showed this variety of combinations of colors. Laboratory observations did not show any relationship between coloration and intermolt stage. Although newly settled J1 crabs were totally white shortly after metamorphosis, 24 to $48 \mathrm{~h}$ after molting their legs turned pink, brown, or purple, while the carapace remained white. We maintained crabs in the laboratory $(n=15)$ to observe if changes in colors occurred between 2 intermolt stages, but it rarely happened (for crabs smaller than J4). Only in 1 case did the color change from white to brown.

The proportion of juvenile crabs smaller than J3 and larger than J4 with adult-like coloration (purple) was estimated for the 3 habitats sampled over time. Not all the habitats were used because of the low number of crabs found in some of them, or because only 1 stage was found. In shell hash with boulders, only $8 \%$ of the smaller crabs showed adult-like coloration, while $43 \%$ of the larger juveniles were similar in colors to the adults. In sand with boulders, $12 \%$ of the smaller crabs and $45 \%$ of the $>\mathrm{J} 4$ crabs showed similar coloration to the adults. In rock platform with boulder, no crab > J4 was found and $15 \%$ of the smaller crabs (all J1) were purple. Similar patterns were found in the samples conducted over time (2 summers); the proportion of purple crabs $<\mathrm{J} 3$ was small. 


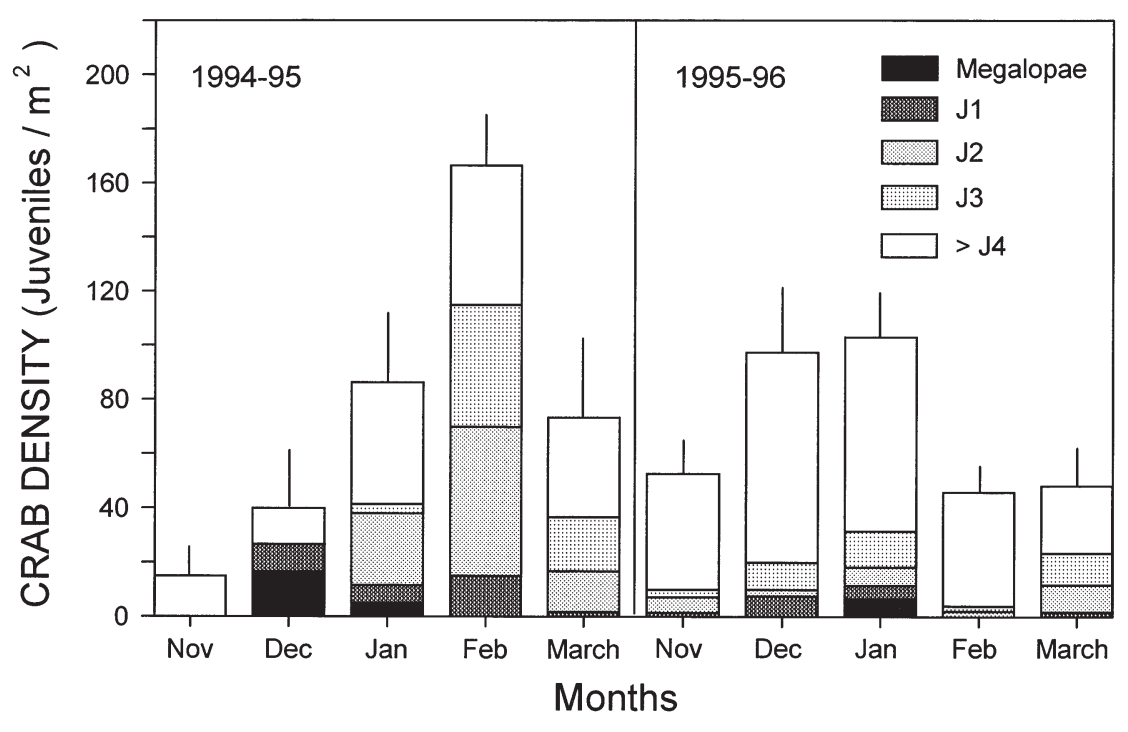

Fig. 5. Homalaspis plana. Density of megalopae and juvenile stone crabs by instar stage in 1 sampling location throughout the settlement/post-settlement season (November to March) during 2 consecutive years (1994-95, and 1995-96). In all cases $100 \%$ boulder cover (over the different substrate types) was sampled. Vertical lines: $1 \mathrm{SE}$ (for all groups together)

\section{Laboratory experiments}

Habitat preference

Juvenile stone crabs preferred shell hash (40 crabs) over sand (5 crabs; $^{2} \chi^{2}=27.22, \mathrm{df}=1, \mathrm{p}<$ 0.001 ), and boulders (39 crabs) over sand $\left(8\right.$ crabs; $\chi^{2}=20.45$, $\mathrm{df}=1, \mathrm{p}<0.001$ ). No preference was detected when crabs were allowed to choose between shell hash $(21$ crabs $)$ and boulders $\left(27\right.$ crabs; $\chi^{2}=0.75, \mathrm{df}=1,0.1<\mathrm{p}$ $<0.5$ ). Habitat preference was independent of crab size (megalopae, J1, J2, J4 and >J4) for all the habitat choice combinations (bare sand vs shell hash: $\chi^{2}=4.6$, $\mathrm{df}=4,0.1<\mathrm{p}<0.5$; bare sand vs boulders: $\chi^{2}=8.26, \mathrm{df}=4,0.05<\mathrm{p}$ $<0.1$; shell hash vs boulders: $\chi^{2}=$ $5.55, \mathrm{df}=4,0.1<\mathrm{p}<0.5$ ).
Availability of suitable habitats

The 2 dominant substrates in El Quisco MEA are rocks $(\bar{X}=64.8 \%$ cover, $\mathrm{SE}=19.4)$ and shell hash $(\bar{x}=$ $35.6 \%, \mathrm{SE}=9.2$ ). When rocks (boulders and platforms) were the substrates, boulders were also present in $61 \%$ of the total area covered by rocks. Of the total area that had shell hash as substrate, $90 \%(\mathrm{SE}=2.2)$ had boulders. The Las Cruces MPA showed a 96.8\% of the total area with rock as substrate and $3.2 \%$ with shell hash. Of the total area covered by rock, only $5.1 \%$ had rock with boulders, while boulders were present in $24.5 \%$ of the area covered with shell hash. Sand, a common and suitable habitat for stone crab recruitment, was not present in either of the 2 protected areas. Las Cruces MPA is located in a very unprotected area in comparison to El Quisco, which in turn is more exposed than our most exposed monitoring site.

\section{Spatial micro-scale distribution of juvenile crabs}

ANOVAs were conducted to test for the effect of coexisting species on juvenile crab abundance $(<\mathrm{J} 2$ and $>$ J3). Only amphipods had an effect on crab density (on $<\mathrm{J} 2$ and total crab, but not $>\mathrm{J} 3$; Table 5). The density of juvenile stone crabs was higher when abundance of amphipods was also higher. Abundance of the other 2 species did not show any effect on abundance of juvenile stone crabs (Table 5).

\section{Interspecific competition}

In all the experimental trials $(\mathrm{n}=8)$, no spatial segregation between juvenile stone crabs and Petrolisthes spp. was observed (in $40 \%$ of the trials the stone crabs were sheltered with 2 Petrolisthes spp., and in the remaining cases the stone crabs and the 3 Petrolisthes spp. were sheltered together). These results are consistent with field data. One juvenile stone crab was missing, probably due to cannibalism.

Table 5. Homalaspis plana. Results of 1-way ANOVAs conducted to assess if abundance of juvenile stone crabs was affected by the relative abundance of the most conspicuous species in the intertidal zone. The habitat sampled (S/B-T) was the most suitable (based on density) for juvenile stone crabs. Sample size was 36, thus in all cases df $=3,32$. Data were not transformed because the assumptions of ANOVA were met

\begin{tabular}{|llcc|}
\hline Species & Instar & $\mathrm{r}$ & $\mathrm{p}$ \\
\hline Amphipods & $<\mathrm{J} 2$ & 3.02 & 0.043 \\
& $>\mathrm{J} 3$ & 2.73 & 0.060 \\
& Total & 7.53 & 0.006 \\
Petrolisthes spp. & $<\mathrm{J} 2$ & 0.81 & 0.498 \\
& $>\mathrm{J} 3$ & 0.19 & 0.899 \\
& Total & 0.13 & 0.942 \\
Tegula atra & $<\mathrm{J} 2$ & 2.52 & 0.075 \\
& $>\mathrm{J} 3$ & 0.35 & 0.780 \\
& Total & 1.39 & 0.261 \\
\hline
\end{tabular}


Intraspecific interactions

Intraspecific competition. There was no clear pattern of habitat use or spatial segregation of younger juveniles to less suitable habitats (sand) when larger conspecifics were present. When 3 crabs were present ( 2 J1 and $1 \mathrm{~J} 2$ ), 1 of the 3 crabs was found at one boulder and the others at the second boulder (in $80 \%$ of the cases); in $75 \%$ of the cases the larger instar (J2) was alone. Crab losses, mostly on J1, were detected (40\% of the crabs). When a combination of J1 to J3 instar crabs was used ( $\mathrm{n}=4$ crabs per tank), a single crab per boulder was found in $50 \%$ of the cases, and the remaining crabs were either at the second boulder or buried in bare sand. Exclusion of smaller crabs was not detected as in the previous case; the same proportion of each instar stage was found alone. A loss of $70 \%$ was estimated for this instar combination.

Cannibalism. First and second instar crabs were cannibalized by larger conspecifics, and the cannibalism rate depended on prey density (ANOVA J1: $F=11.01$, $\mathrm{df}=5,31, \mathrm{p}<0.00001 ; \mathrm{J} 2: F=2.48, \mathrm{df}=5,51, \mathrm{p}=0.043$; Fig. 6). In the control tanks, $100 \%$ survival was found for all crab density treatments. For J1, 3 homogeneous groups were detected using multiple comparisons: (1) 1 to 3 crabs per tank, (2) 2 to 4 crabs per tank, and (3) 6 to 8 crabs per tank. Multiple comparisons did not have enough power to detect which treatments were different for J2 prey. Proportional mortality was not significantly different among prey densities (ANOVA:
$F=0.048, \mathrm{df}=5,82, \mathrm{p}=0.78$ ) or predator size (ANOVA: $F=2.7$, df $=1,82, \mathrm{p}=0.10)$. The interaction term was not significant $(\mathrm{p}=0.41)$.

Cannibalism experiments at variable densities of predators showed that mutual interference may not affect survival of younger conspecifics. Mean consumption rate was higher when more predators were present (ANOVA: $F=4.59$, df $=1,18, \mathrm{p}=0.04 ; 1$ predator: 1.6 prey consumed [SE $=1.2]$; multiple predators: 4.0 prey consumed [SE $=1.5]$ ), but no differences in mean proportional prey mortality per predator were detected (ANOVA: $F=0.36$, df =1,18, p=0.56). Mean predator size was not significantly different between the single and multiple predator treatments $(t$-test $=1.737, \mathrm{df}=$ 38, $\mathrm{p}>0.05)$.

\section{DISCUSSION}

Recruitment of the stone crab Homalaspis plana in the intertidal zone was influenced by wave exposure and substrate type. The most suitable intertidal sites for recruitment of young-of-the-year $H$. plana were areas sheltered from wave action. Wave action seems to be a major determinant of juvenile abundance, despite our exposed sites not being the most exposed locations in the area. Preliminary data using small crab pots $(25 \times 25 \mathrm{~cm})$ showed that juveniles of $H$. plana occur also in shallow subtidal zones (Fernández unpubl. data). Recruitment of $H$. plana in subtidal zones is not yet known, but preliminary surveys in shell hash suggest that density of juveniles in subtidal areas is relatively low compared to the intertidal area (A. Palma unpubl. data).

Abundance of megalopae was similar across sheltered and exposed sites, although presence of megalopae in the samples is not a direct indicator of larval supply. The pattern of abundance over time for subsequent stages changed among habitats. For newly settled crabs (J1 and J2) a faster decline in crab density was detected at the exposed site in comparison to the sheltered sites. The losses could be due to natural mortality, or postsettlement emigration to more suitable habitats. Growth to the next intermolt stage alone is not likely to explain the changes in instar composition in the exposed monitoring site (S/B-E) throughout the summer. Based on our observations of growth through the summer and size at instar, J1 and J2 crabs found in Janu-

ary could not be among the >J4 crabs
Fig. 6. Homalaspis plana. Cannibalism rate for 2 prey types (J1 and J2), and different prey densities under laboratory conditions. Larger predators were used for larger prey (J2). We report mean number of prey eaten $\mathrm{d}^{-1}$ (top panels), and mean proportional mortality (bottom panels). Vertical lines: $1 \mathrm{SE}$ 
that comprised most of the sample in February. In protected habitats, the decrease in settled crab (J1-J2) density over time can be explained by growth to the larger intermolt stages, and also by natural losses (natural mortality or emigration).

Substrate type is also an important determinant of juvenile stone crab abundance both in sheltered and exposed sites. Bare substrates (sand, shell hash and rock) showed low abundance or complete lack of juveniles, while the highest crab densities were found in substrates with boulders. The pattern of abundance of recruits and instar composition (especially in sheltered zones, where density was higher and a larger variety of habitats were sampled) showed variation among substrates. Rock platform with boulders showed the highest density of newly settled crabs, but no crabs were found shortly after settlement. In contrast, the most suitable habitat (based on total juvenile crab abundance) showed the lowest density of newly settled crabs and the highest density of larger conspecifics. Our sampling and experimental design shows clear differences in recruitment among substrates or exposure to wave action, but does not allow identification of the main processes that could account for those differences: (1) differences in larval supply, (2) habitat choice or migration between habitats, (3) differential post-settlement survival among habitats (e.g. due to fish or other predators), and (4) intraspecific interactions (e.g. competition or cannibalism).

Differences in larval supply at small spatial scales may occur especially if we consider the differences in wave exposure. Based on the information available, it is difficult to conclude if higher abundance of recruits in sand with boulders (S/B) is the result of larval supply, habitat choice, or other processes. Laboratory experiments showed that juvenile crabs prefer shell hash, or boulders over bare sand, but sandy substrates are only found in sheltered areas in the field. We do not have evidence of differences in larval supply, but in other geographic areas differences in larval abundance have been detected at a similar spatial scale (e.g. Eggleston \& Armstrong 1995). The habitat with the highest recruitment density is near an area characterized as the best fishing ground for locos, the most valuable shellfish of Chile (local fishermen pers. comm.) This observation suggests that recruitment of other invertebrates with planktonic larvae may also be high if the same oceanographic processes affect larval transport of these invertebrate species in a similar fashion.

Migration between habitats may also be a plausible process to explain the differences in instar composition over time in the different habitats sampled. We are not aware of the potential for migration of juvenile stone crabs, and think that migration between the habitats (sites) sampled is unlikely. However, post-settlement distribution of juveniles crabs has been reported for other species (Moksnes 1999) and it may occur at small spatial scales, or between intertidal and subtidal habitats. We also think that migration between habitats is more likely to occur among larger juveniles since they tend to concentrate in a few habitat types, while younger conspecifics seem to be less selective and are found in a wider range of habitats.

The effect of post-settlement survival in different substrate types may also play a role, although it is important to point out in this present study that substrates with similar characteristics (boulders) were compared. Predation by fish or other visual predators may be important judging from the polychromatism observed among smaller crabs. Polychromatism has been shown to confer an advantage to juvenile crabs of Cancer irroratus when visual predators were present (Palma 1998). When crabs reach the size where they are no longer vulnerable to predation, juvenile crabs acquire the adult, monochromatic coloration (Palma 1998). We observed that early stages of Homalaspis plana also show polychromatism, with a higher proportion of non-adult ('others') coloration among smaller than among larger conspecifics. After a 15 to $20 \mathrm{~mm}$ $\mathrm{CW}$ is attained, the frequency of adult-like monochromatic juveniles increases. This suggests that visual predators may exert an important source of mortality among juveniles of this species in all substrate types, considering that the percentage of adult-like early stage juveniles does not vary among the habitats occupied by $H$. plana. In Chile, fish predation on crabs seems to be higher than that observed for $C$. irroratus in Maine (A. Palma pers. comm.)

Finally, another factor that may affect recruitment patterns of Homalaspis plana is intraspecific interactions, namely competition and cannibalism. Intraspecific competition does not appear to be important based on the laboratory experiments, since juveniles of different sizes occupied the same microhabitat. These results suggest that aggressive interaction or spatial competition should not produce spatial segregation of the different instars; these results are consistent with field data. However, both laboratory experiments and patterns of abundance of juvenile crabs in the field indicate that cannibalism among youngof-the-year may occur, suggesting that intraspecific interactions may not have an effect on habitat choice, but rather on survival. Furthermore, the experiments conducted suggest that smaller crabs may not find refuge either at low prey densities, or at high densities of predators (larger conspecifics) as in other crab species (Moksnes et al. 1997, Fernández 1999), since proportional mortality of prey is not affected by prey or predator densities. J2 prey seem to be equally as 
vulnerable as $\mathrm{J} 1$, at least for the predator size observed in the field and used in our experiments. We recognize the limitations of laboratory experiments (in our case no alternative prey were used, nor shelters), and do not intend to extrapolate cannibalism rates or density-dependent cannibalism functions from the laboratory scale to the field. However, we think that laboratory experiments under controlled conditions may still help to explain the patterns found in the field, especially considering previous evidence of cannibalism among juvenile crabs from laboratory and field experiments (e.g. Fernández et al. 1993a,b, Visser 1997, Moksnes et al. 1998, Moksnes 1999). Cannibalism is a common response among juvenile crabs (Fernández et al. 1993a,b, Visser 1997, Moksnes et al. 1997, 1998, Moksnes 1999, Fernández 1999), and some of these studies suggest that the cannibalism rate may not be affected by the presence of shelters (Fernández et al. 1993a), and that the effect of alternative prey is not always clear (Visser 1997). We think that lower recruitment in habitats occupied by larger conspecifics (S/B-T) in comparison to other sheltered habitats may be the result of cannibalism among juveniles, especially when densities of larger juveniles is high. Furthermore, we suggest that the differences in recruitment (as indicated by the abundance of megalopae, J1, and J2) between years could also be due to cannibalism among juveniles. In the 1994-95 season, abundance of larger conspecifics was lower (half) and abundance of recruits was higher (3-fold) than in 1995-96. We do not have evidence of differences in larval supply to support our suggestion, but both differences in larval supply as well as intraspecific interactions could be plausible explanations for the different patterns of recruitment and instar composition between years. Another plausible explanation is differential predation, by fish or other predators, between years, or other types of interspecific interactions. In the 1995-96 season, we observed a large amount (not quantified) of newly settled Paraxanthus barbiger, a species that was rare in the previous settlement season. Other species not considered here may also affect the pattern of abundance of juvenile $H$. plana. However, the most conspicuous species do not seem to have any effect on abundance of juvenile stone crabs, based on correlation analyses and on laboratory experiments. Only amphipods, which may serve as food items of crabs, showed some association with larger stone crabs.

The present study contributes not only to the understanding of the early life-history and ecology of a heavily exploited species, but also sheds light on the factors that should be considered in the design of MPAs in general, and MEAs in Chile. Our study also shows that suitable habitats for the stone crab (combining sub- strate type and shore exposure) are scarce both in the marine reserve of Las Cruces and the MEA of El Quisco. Other lower quality habitats for crab recruitment were present, but a predominance of unsuitable habitats for this crab species was found. Although these conclusions are made based on only 2 closed areas, more than $95 \%$ of the MEAs existing along the $4200 \mathrm{~km}$ coastline of Chile (>150 MEAs) include locos as the main target, suggesting that similar, exposed habitats may predominate in most of them. MPAs should contain a variety of microhabitats at a spatial scale that allows the maintenance of local populations of species with different life histories and vagility characteristics, as well as ecological processes affecting the ecosystem. In general, reserves placed in areas of high-quality habitat are expected to outperform those located in marginal habitats (Roberts 1998). The goal set 15 yr ago, when the Las Cruces Marine Reserve was created, was to evaluate the effect of human exclusion on the ecosystem. Thus, all the considerations regarding the appropriate size of the MPA, or presence of different microhabitats, were not under consideration. Considerations about habitat quality for all benthic exploited species is a critical factor in the design of MEAs, which are currently increasing in number in Chile. Fishermen select the MEAs that will be proposed to the Fisheries Administration using their knowledge of historical catches of locos Concholepas concholepas, so that those areas contain suitable habitats for some benthic species. In fact, in the El Quisco MEA abundance of locos is much higher than in open access fishing grounds; a similar pattern of species abundance was reported for sea urchins and limpets (Pino \& Castilla 1995, Castilla \& Pino 1996). All these species inhabit similar habitats and are found at exposed sites. In contrast, Homalaspis plana abundance has not increased in the closed area for $5 \mathrm{yr}$, although this species also inhabits rocky areas (Fernández \& Castilla 1997) and is heavily exploited by the same fishing fleet. We think that both the lack of suitable substrate and exposure to wave action are major factors affecting the success of the MPAs and MEAs for the stone crab. Neither of these factors are currently considered in the assignation or planning of MEAs, although they could explain the lack of effect of both protection strategies in increasing the abundance of the stone crabs in Chile in comparison with other exploited benthic species. Other factors, such as coastal circulation, larval dispersal and connectivity between MPAs and MEAs are also of major importance (Allison et al. 1998), but until more information about their effects becomes available, simple factors such as habitat quality for the most exploited benthic species could be used for a better design of marine preserves and assignation of management areas. 
Acknowledgements. We thank Oriana Campodonico, who kindly helped us in field and laboratory work during her research training. We also thank Cristián Pacheco for helping us to place and record wave impact measurements, and Marcelo Rivadeneira and Fernanda Oyarzún for their help in surveying and assessing habitat types and percent cover of each substrate type in closed areas (Las Cruces MPA and El Quisco MEA). We are very thankful to Alvaro Palma, PerOlav Moksnes, and 2 anonymous reviewers for their very helpful comments. M.F. acknowledges FONDAP funding (Program No. 3) while conducting data analysis and writing of this manuscript. J.C.C. acknowledges financial support from the 1996 Cátedra Presidencial en Ciencias.

\section{LITERATURE CITED}

Allison G, Lubchenco J, Carr M (1998) Marine reserves are necessary but not sufficient for marine conservation. Ecol Appl 8:S79-S92

Antezana T, Fagetti E, López MT (1965) Observaciones bioecológicas en decápodos comunes de Valparaíso. Rev Biol Mar 12:1-60

Bell J, Westoby M (1986) Abundance of macrofauna in dense seagrass is due to habitat preference, not predation. Oecologia 68:205-509

Botero L, Atema J (1982) Behavior and substrata selection during larval settling in the lobster Homarus americanus. J Crustac Biol 21:59-69

Carvacho A, Tapia R, Vidal C (1995) Aspectos reproductivos de la jaiba mora Homalaspis plana (Milne-Edwards 1834) (Crustacea: Brachyura: Xanthidae) en el seno de Reloncavi, Chile. Biol Pesq 24:7-15

Castilla JC (1994) The Chilean small-scale benthic shellfisheries and the institutionalization of new management practices. Ecol Int Bull 21:47-63

Castilla JC (1996) La futura red chilena de parques y reservas marinas y los conceptos de conservación, preservación y manejo en la legislación nacional. Rev Chil Hist Nat 69: $253-270$

Castilla JC (1999) Coastal marine communities: trends and perspectives from human-exclusion experiments. TREE 14: 280-283

Castilla JC, Durán L (1985) Human exclusion from the rocky intertidal zone of Central Chile: the effects of Concholepas concholepas (Gastropoda). Oikos 45:391-399

Castilla JC, Pino C (1996) The small-scale fishery of the red sea urchin, Loxechinus albus, in Chile and the Management and Exploitation Area of Caleta El Quisco. Out of the Shell 5:5-8

Castilla JC, Manríquez P, Alvarado J, Rosson A, Pino C, Espoz C, Soto R, Oliva D, Defeo O (1998a) Artisanal Caletas as unit of production and co-management of benthic invertebrates in Chile. Can Spec Publ Fish Aquat Sci 125:407-414

Castilla JC, Steinmiller DK, Pacheco CJ (1998b) Quantifying wave exposure on the intertidal rocky shore of central Chile. Rev Chil Hist Nat 71:19-25

Castro P (1978) Settlement and habitat selection in the larvae of Echinoecus pentagonus, a brachyuran symbiotic with sea urchins. J Exp Mar Biol Ecol 34:259-270

Durán L, Castilla JC (1989) Variation and persistence of the middle rocky intertidal community of Central Chile, with and without human harvesting. Mar Biol 103:555-562

Eggleston D, Armstrong D (1995) Pre- and post-settlement determinants of estuarine Dungeness crab recruitment. Ecol Monogr 65:193-216

Eggleston D, Lipcius R, Miller D, Coba-Cetina L (1990) Shel- ter scaling regulates survival of juvenile Caribbean spiny lobster Panulirus argus. Mar Ecol Prog Ser 62:79-88

Fagetti E (1960) Primer estadío larval de cuatro Crustáceos Braquiuros de la Bahía de Valparaíso. Rev Biol Mar 10: 134-154

Fernández M (1999) Cannibalism in Dungeness crab Cancer magister: effects of predator-prey size ratio, density, and habitat type. Mar Ecol Prog Ser 182:221-230

Fernández M, Castilla JC (1997) The Chilean artisanal stone crab (Homalaspis plana) fishery: catch trends in open access zones and the effects of management areas in Central Chile. J Shellfish Res 16:371-377

Fernández M, Iribarne O, Armstrong DA (1993a) Habitat selection by young-of-the-year Dungeness crab, Cancer magister Dana and predation risk in intertidal habitats. Mar Ecol Prog Ser 92:171-177

Fernández M, Armstrong D, Iribarne O (1993b) First cohort of young-of-the-year Dungeness crab reduces abundance of subsequent cohorts in intertidal shell habitats. Can J Fish Aquat Sci 50:2100-2105

Godoy C, Moreno CA (1989) Indirect effects of human exclusion from the rocky intertidal in southern Chile: a case of cross-linkage between herbivores. Oikos 54:101-106

González E, Villouta E, Giovanni D (1997) Diagnóstico y análisis para el diseño de un sistema nacional de reservas marinas. Fond Invest Pesq (96-52)

Hedvall O, Moksnes PO, Pihl L (1998) Habitat selection in postlarvae and juveniles of the shore crab, Carcinus maenas: a laboratory study in an annular flume. Hydrobiologia 375/376:89-100

Herrnkind WF, Butler MJ (1986) Factors regulating postlarval settlement and juvenile microhabitat use by the spiny lobster Panulirus argus. Mar Ecol Prog Ser 34:23-30

Iribarne O, Fernández M, Armstrong DA (1994) Does space competition regulate density of juvenile Dungeness crab Cancer magister Dana in sheltered habitats? J Exp Mar Biol Ecol 183:259-271

Iribarne O, Armstrong DA, Fernández M (1995) Environmental impact of intertidal juvenile Dungeness crab habitat enhancement: effects on bivalves and crab foraging rate. J Exp Mar Biol Ecol 192:173-194

Keough M, Downes BJ (1982) Recruitment of marine invertebrates: the role of active larval choices and early mortality. Oecologia 54:348-352

Luckenbach MW (1984) Settlement and early post-settlement survival in the recruitment of Mulinia lateralis (Bivalvia). Mar Ecol Prog Ser 17:245-250

Mansour R, Lipcius R (1991) Density-dependent foraging and mutual interference in blue crabs preying upon infaunal clams. Mar Ecol Prog Ser 72:239-246

Moksnes PO (1999) Recruitment regulation in juvenile shore crabs Carcinus maenas: importance of intraspecific interactions in limited refuge habitats. PhD dissertation, Göteborg University

Moksnes PO, Lipcius RN, Pihl L, van Montfrans J (1997) Cannibal-prey dynamics in juveniles and postlarvae of the blue crab. J Exp Mar Biol Ecol 215:157-187

Moksnes PO, Pihl L, van Montfrans J (1998) Predation on postlarvae of the shore crab Carcinus maenas: importance of shelter, size and cannibalism. Mar Ecol Prog Ser 166: 211-225

Morales C, Antezana T (1983) Diet selection of the Chilean Stone crab Homalaspis plana. Mar Biol 77:79-83

Moreno CA, Luneke KM, Lopez MI (1986) The response of an intertidal Concholepas concholepas (Gastropoda) population to protection from man in southern Chile and effects on benthic assemblages. Oikos 46:359-364 
Palma AT (1998) Early post-settlement ecology of large benthic decapod crustaceans in the Gulf of Maine. PhD dissertation, Department of Oceanography, University of Maine, Orono

Payne H, Castilla JC (1994) Socio-biological assessment of common property resource management: small scale fishing Unions in Central Chile. Out of the Shell 4:10-14

Pino C, Castilla JC (1995) The key-hole limpets (Fisurella sp.) in the Chilean artisanal fishery. Out of the Shell 5:8-10

Editorial responsibility: Otto Kinne (Editor), Oldendorf/Luhe, Germany
Roberts C (1998) Sources, sinks, and the design of marine reserve networks. Fisheries 23:16-19

Visser E (1997) Competition, cannibalism, and prey limitation: factors compromising the effectiveness of shell habitat mitigation for early benthic phase Cancer magister in Grays Harbor, WA. PhD dissertation, University of Washington, Seattle

Zar J (1996) Biostatistical analysis, 3rd edn. Prentice Hall, Upper Saddle River, NJ

Submitted: October 28, 1999; Accepted: May 4, 2000

Proofs received from author(s): November 9, 2000 